\title{
MPPT Algorithm Based on the Perturbation and Observation with Variable Metric
}

\author{
Yishuang $\mathrm{Hu}^{1, \mathrm{a}}$, Zimu Zhang ${ }^{1}$, Dong zhao ${ }^{1}$, Yue Deng ${ }^{1}$, Jingyi $\mathrm{Lu}^{1}$ \\ 1. School of electric power engineering, North China Electric Power University, \\ Baoding 071000, China; \\ 273415335@qq.com
}

Keywords: uniform illumination; the Perturb and Observe (P\&O); Variable metric

\begin{abstract}
The output of photovoltaic array under uniform light is nonlinear with single peaks. Among the MPPT strategies, The P\&O Maximum Power Point Tracking algorithm is mostly used, due to its ease of implementation. However, its main drawbacks are the waste of energy in steady conditions, when the working point moves across the MPPT and the poor dynamic performances exhibited when a step change in solar irradiance or in temperature occurs. Because of this disadvantage, $\mathrm{P} \& \mathrm{O}$ based on variable metric method is proposed. Combining these two algorithms, use variable metric can automatic change the step-size during the process. Compared with the conventional fixed step size method, the proposed approach can effectively improve the MPPT speed and accuracy simultaneously. A theoretical analysis and the design principle of the proposed algorithm are provided and its feasibility is also verified by simulation.
\end{abstract}

\section{Introduction}

Maximum power point tracking is an important part in photovoltaic power generation system, which can transmit the maximum power of panels array to the inverter system. The control methods of MPPT in common use is traditional P\&O. The principle of this is comparing the incongruous difference value of power. It will maintain the perturbation direction of duty cycle if the difference value is positive, otherwise the duty cycle will perturb in the opposite direction if the difference value is negative, the peculiarity of which is higher tracking efficiency, rapid tracking velocity, less influenced by environment and the defect is it is vibrate obviously at MPPT, which wastage a part of energy.

In this paper, it presents the control arithmetic of MPPT of variable step that based on variable metric method to overcome the defect of traditional P\&O, which can decrease the vibrate wastage at MPPT and increase the tracking speed and transfer efficiency of system effectively. On the promise of homogeneous illumination and temperature, adjusting step dynamically makes the given voltage approach the MPPT point to achieve the effect of rapid tracking[1-4].

\section{The output characteristic of photovoltaic array}

The photovoltaic cell panels can be considered as the current supply that generate the light current steadily, paralleled with a diode which under the positive bias and a parallel resistance ${ }^{R_{s h}}$.Obviously, ${ }^{I_{p h}}$ offers the forward current $I_{d}$ and the shunt current of the diode. The surplus current outflows a photovoltaic cell and enters into the load ${ }^{R_{L}}$ passing by a series resistor. the expression of the output current is[5]

$$
\begin{gathered}
I=I_{p h}-I_{d}-I_{s h} \\
I=I_{p h}-I_{0}\left\{\exp \left[q \frac{\left(V+I R_{s}\right)}{A K T}\right]-1\right\}-\frac{\left(V+I R_{s}\right)}{R_{s h}}
\end{gathered}
$$

Where $I_{0}$ is the dark current of the cell. $\mathrm{V}$ is the output voltage. The electron charge is $\mathrm{q} 1.6 \times 10^{-19} \mathrm{C}$. $\mathrm{K}$ is Boltzmann constant $1.38 \times 10^{-23} \mathrm{~J} / \mathrm{K} . \mathrm{T}$ is thermodynamics. A is P-N junction's ideal factor, 
valuing 2.8 when the temperature is $278 \mathrm{k}$.

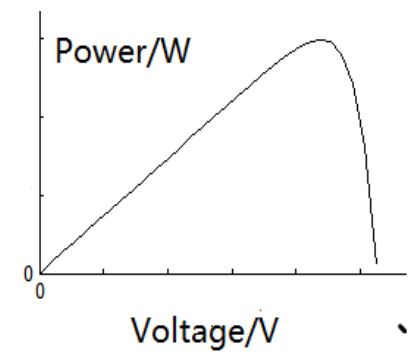

Fig.1 The output characteristic of a single PV model

\section{The model of maximum power point}

There is a maximum power point $P_{0}$ of the system under every environmental state and this point will change accordingly as the environmental state changes. When the temperature and illumination intensity are both different, in order that the cell can work at the best point under the current outside condition, use a definite method to make the cell work at the maximum power point from beginning to end when the maximum power point drifts. The method is named Maximum power point tracking, that is MPPT.

\section{Modified perturbation and observation method based on variable scale}

Traditional P\&O comparing the incongruous difference value of power. It will maintain the perturbation direction of duty cycle if the difference value is positive, otherwise the duty cycle will perturb in the opposite direction if the difference value is negative. However the obvious defect is the vibration wastage around MPPT. The small step leads the tracking speed slow and the large step leads to a fast tracking speed but the vibration at MPPT is more obvious. When the environment makes a rapid change, it will not only increase the vibrate wastage but also occurs the misjudgment in the system. When working at the MPPT, the system will produce vibration around MPPT.

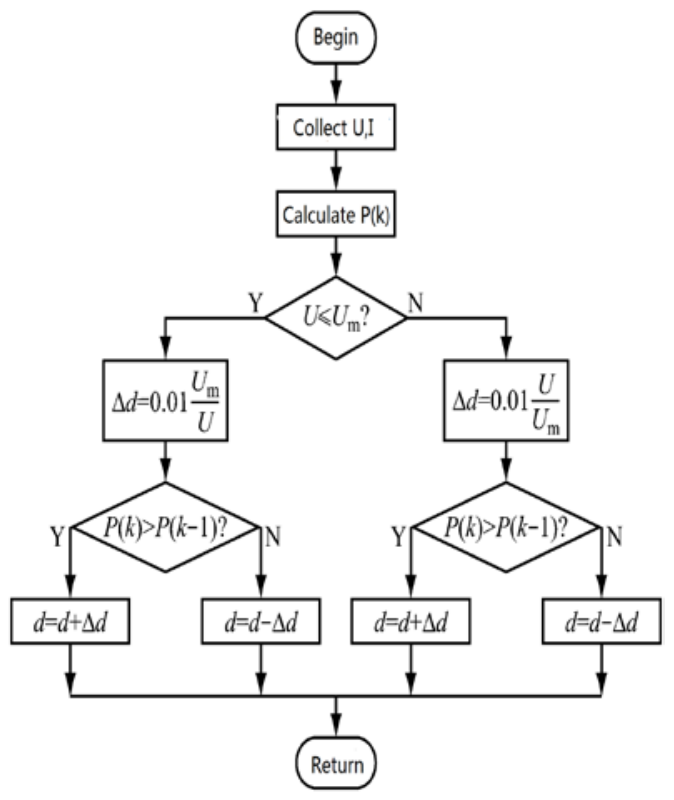

Fig.2 The flow chart of traditional P\&O

Because the veracity of the $\mathrm{P} \& \mathrm{O}$ affected by the step, it is important to choose the step. The core idea of combining the variable metric method with $\mathrm{P} \& \mathrm{O}$ is changing the given step into metabolic step and step formula into variable metric function. It can improve the P\&O to adjusting the step 
dynamically. This make the maximum power point approach the practical maximum power point, which improve the searching speed and the optimizing precision. The modified P\&O estep will change along the iterative algorithm. The Heather matrix and grads function are changing along with the increase of the times of iteration in the operating progress.

In the progress of iteration, the particle updates its position and speed constantly based on the individual extreme value and optimal solution. The formula is as shown.

$$
\begin{aligned}
& v_{i, j}^{t+1}=w v_{i, j}^{t}+c_{1} r_{1}\left(p_{i, j}-x_{i, j}^{t}\right)+c_{2} r_{2}\left(p_{g, j}-x_{i, j}^{t}\right) \\
& x_{i, j}^{t+1}=x_{i, j}^{t}+v_{i, j}^{t+1}, j=1,2, \ldots, d
\end{aligned}
$$

Where $\mathrm{X}, \mathrm{v}$-the position and vector speed. C1C2-positive learning factor.

$R 1$ and $R 2-$ uniform distribute random number among 0 to 1.

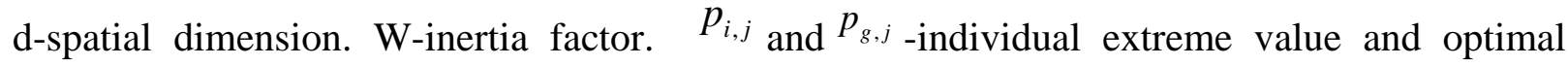
solution

Obtain the photovoltaic array power, variable voltage and initial expression under the certain illumination by scanning. Evaluate the grads expression of several power and variable voltage. Find the norm of variable voltage and its initial Heather array. And set the maximum time of iteration, precision and given value $\mathrm{A}, \mathrm{B}$ (both $\mathrm{A}$ and $\mathrm{B}$ are less than 1 ). After substituting the new voltage, if power $>$ initial voltage power $+\mathrm{B}^{*} \mathrm{~A}^{\wedge}$ iteration time $*$ the grad under initial voltage $*$ the searching direction under initial voltage, the arithmetic will be stopped and outputting the new voltage. Otherwise, keep operating until the voltage power reaches the maximum value.

\section{The MATLAB result of modeling}

Based on the analysis of arithmetic, apply MATLAB to conduct the compare of modeling and simulating between traditional $\mathrm{P} \& \mathrm{O}$ and the $\mathrm{P} \& \mathrm{O}$ based on the modified variable metric method. Take the standard experiment temperature (the degree of 25). The short circuit current and open circuit voltage of photovoltaic module are 7A and 0.6V under the standard illumination (1000). The photovoltaic array receives uneven illumination in the simulation. The illumination condition is shown as table 1 . The three photovoltaic arrays are series connect to each other. Every array contains 15 photovoltaic modules that are series connect, and all these arrays are under the constant and same experiment temperature.

Table1. Array illumination conditions in experiment one

\begin{tabular}{cccc}
\hline Array & Array1 & Array2 & Array3 \\
\hline $\begin{array}{c}\text { Intensity } \\
\text { density } / w / m^{2}\end{array}$ & 3000 & 2250 & 1500 \\
\hline
\end{tabular}

Applying two kind of arithmetic to track the MPP of photovoltaic array, the results about the MPPT of these two methods in simulation are shown as figure3.
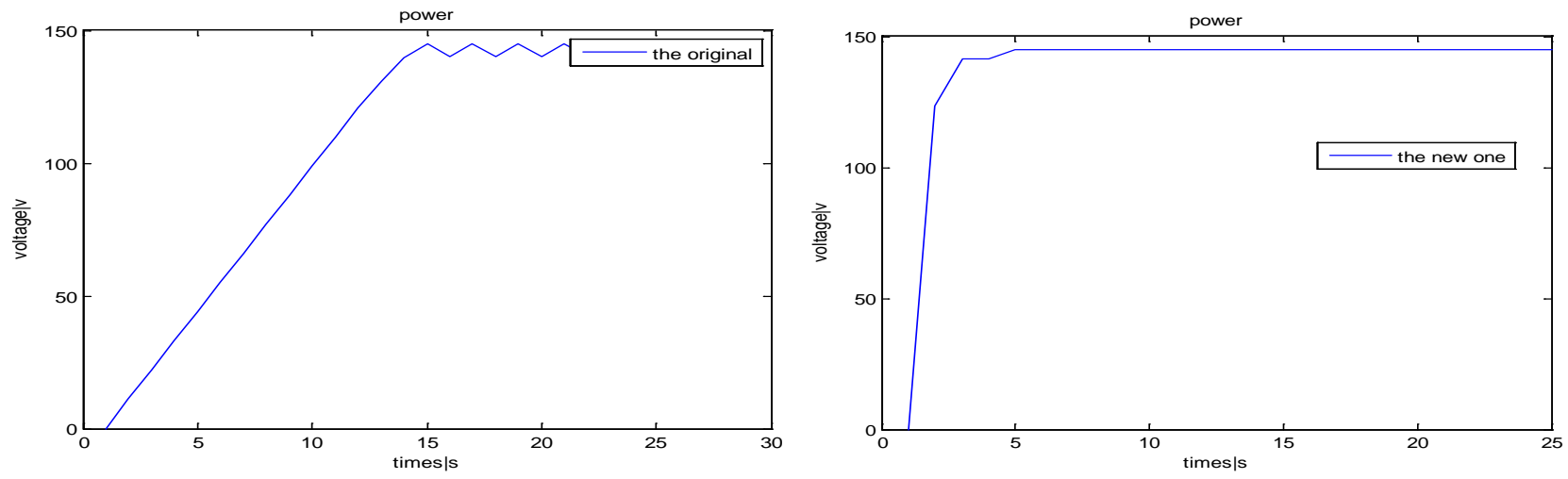

Fig.3 The effect of two MPPT methods on power 
Table2. The comparison of time and MPPT between two method

\begin{tabular}{cccc}
\hline $\begin{array}{c}\text { The traditional } \\
\text { algorithm time/S }\end{array}$ & $\begin{array}{c}\text { The improved } \\
\text { algorithm time/S }\end{array}$ & $\begin{array}{c}\text { The traditional } \\
\text { algorithm of } \\
\text { maximum } \\
\text { power/W }\end{array}$ & $\begin{array}{c}\text { The improved } \\
\text { algorithm } \\
\text { maximum } \\
\text { power/W }\end{array}$ \\
\hline $\begin{array}{c}0.45 \mathrm{~S} \\
\begin{array}{c}\text { Iteration } 15 \text { times } \\
\text { Iteration } 15 \text { times }\end{array}\end{array}$ & $\begin{array}{c}0.002 \mathrm{~S} \\
\text { Iteration } 5 \text { times }\end{array}$ & $144.80 \mathrm{~W}$ & $148.85 \mathrm{~W}$ \\
\hline
\end{tabular}

As figure 3 shown, the traditional $P \& O$ possess the defects that power vibrates sharply and rate of convergence is slow. However the $\mathrm{P} \& \mathrm{O}$ that based on variable metric method can adjust the step to shorten the time of convergence, witch improve the precision of MPP. In the meantime, it solves the problem of power vibration by variable metric method that helps the arithmetic appropriate for the changing external environment more. Improve the photovoltaic array has a better optimizing speed and solving stability at this modified arithmetic of MPPT.

\section{Summary}

The traditional P\&O leads the energy vibrate wastage when passing the MPP under the stable working condition, and it performs worse dynamic response when the illumination or temperature changes. Aiming at the problem above, there presents a method that combing the traditional $\mathrm{P} \& \mathrm{O}$ with variable metric method. There gives the contrast analysis of these two kinds of arithmetic by MATLAB. According the result of simulation, the new method is better than the traditional P\&O in the aspect that finding the MPP of photovoltaic array under the uniform illumination and avoiding power vibration. In conclusion, the new method can realize the MPPT in a more stable and more precise way.

\section{References}

[1] YU Shijie,HE Huiruo,CAO Renxian,Comparison of MPPT and CVT control in photovoltaic water pump system[J],Acta Energiae Solaris Sinica,1998 19(4): 394-398.

[2] ZHOU Ling,WU Jian,LI Qiuhua,et,Overview of maximum power point tracking control for photovoltaic array[J],High-Voltage Technology,2008 22(6) :1145-115.

[3] Chee Wei Tan, Green T C,Hernandez-Aramburo C A.An improved maximum power point tracking algorithm with current mode control for applications[C]// International Conference on Power Electronics and Drives Systems.Kuala Lumpur, Malaysia, 2005: 489-494.

[4] Fangrui Liu,Shanxu Duan,Fei Liu,et al.A Variable Step Size INC MPPT Method for PV Systems[J].IEEE Transactions Industrial Electronics,2008 55(7): 2622-2628.

[5] Feina N,Petrone G,Spagnuolo G,et al .Optimization of perturb and observe maximum power point tracking method[J],IEEE,Transactions on Power, Electronics, 2005,20(4): 963-973. 